\title{
Simulation-based education to promote confidence in managing clinical aggression at a paediatric hospital
}

Marijke Mitchell ${ }^{1,2,3^{*}}$ (D), Fiona Newall ${ }^{2,3,4,5}$, Jennifer Sokol ${ }^{2,6}$, Melissa Heywood ${ }^{6}$ and Katrina Williams $2,3,7$

\begin{abstract}
Background: An increasing number of incidents involving aggressive behaviour in acute care hospitals are being witnessed worldwide. Acute care hospital staff are often not trained or confident in managing aggression. Competent management of clinical aggression is important to maintain staff and patient safety. Training programmes for acute care staff are infrequently described in the literature and rarely reported for paediatric staff. Simulation training allows practice of skills without patient risk and may be more effective than traditional teaching formats for aggression management.

Aim and design: The aim of this proof of concept study was to develop a simulation-based education session on aggression management for acute care paediatric staff based on best practice principles, to evaluate the acceptability of this training programme and to gain an understanding of the impact of the training on participants' perceived confidence in managing clinical aggression. Two separate simulation exercises were delivered as a 2-h component of a hospital management of clinical aggression (MOCA) training day. Participants completed a written survey immediately prior to, at completion of the simulation-based group training, and at 3-6 months following the simulation training.

Findings: Nine training days were conducted in 2017 for nursing, medical, allied health, education and security staff with a total of 146 participants (83\% were acute care nurses). Two thirds (68\%) of participants had experienced clinical aggression as part of their routine work, with $51 \%$ overall reporting a lack of confidence managing these patients. Immediately following the simulation training, $80 \%$ of all participants reported feeling more confident in managing clinical aggression, 47\% reported a 1-point increase in confidence, whilst 33\% of participants reported a 2- or 3-point increase. At 3-6 months post-training, $66 \%$ of respondents $(N=44)$ reported continued confidence in managing aggression with $100 \%$ of participants stating they would recommend simulation training to colleagues.

\footnotetext{
* Correspondence: marijke.mitchell@rch.org.au

${ }^{1}$ Neurodevelopment \& Disability, Royal Children's Hospital, 50 Flemington

Road, Parkville, Victoria 3052, Australia

${ }^{2}$ Department of Paediatrics, The University of Melbourne, 50 Flemington

Road, Parkville, Victoria 3052, Australia

Full list of author information is available at the end of the article
}

C C The Author(s). 2020 Open Access This article is licensed under a Creative Commons Attribution 4.0 International License, which permits use, sharing, adaptation, distribution and reproduction in any medium or format, as long as you give appropriate credit to the original author(s) and the source, provide a link to the Creative Commons licence, and indicate if changes were made. The images or other third party material in this article are included in the article's Creative Commons licence, unless indicated otherwise in a credit line to the material. If material is not included in the article's Creative Commons licence and your intended use is not permitted by statutory regulation or exceeds the permitted use, you will need to obtain permission directly from the copyright holder. To view a copy of this licence, visit http://creativecommons.org/licenses/by/4.0/ The Creative Commons Public Domain Dedication waiver (http://creativecommons.org/publicdomain/zero/1.0/) applies to the data made available in this article, unless otherwise stated in a credit line to the data. 


\begin{abstract}
(Continued from previous page)
Conclusions: Simulation training is an acceptable method of training and shows promise to improve staffperceived confidence for managing behavioural emergencies in acute paediatric health care settings. In addition, there were potential enduring positive impacts at 3 months after the study. Whilst resource and time intensive, further research assessing the benefits of utilising simulation training in this setting is warranted in order to minimise staff burn-out and improve outcomes for these very vulnerable patients.
\end{abstract}

Keywords: Simulation training, Child, Patient harm, Aggression, Patient safety, Health personnel

\section{Background}

Aggression demonstrated by patients in the acute paediatric hospital setting can result in serious self-injury and threaten the safety of their family, staff and other patients [1]. Clinical aggression episodes in child health facilities warranting a coordinated, systematic response are increasing [2-6]. Paediatric hospital staff, whilst required to regularly demonstrate competence in resuscitation and management of the deteriorating child, are often not trained nor tested in the management of clinical aggression [7-13]. Acute hospital staff report a lack of confidence in managing clinical aggression $[7,8,10$, $14,15]$ which, coupled with regular exposure, can lead to high levels of stress and burnout $[9,10,16]$. A lack of confidence in managing clinical aggression can also result in more frequent activations of hospital emergency response systems leading to increased and potentially unnecessary use of chemical and physical restraint and isolation of patients. It is important that staff training methods are effective in increasing staff confidence and skill levels and post-training discussion identifies how to potentially mitigate preventable errors. Paediatric acute health care is a complex specialty encompassing patients with a wide range of developmental levels that operate within an array of unique family centred care systems. Staff need a large set of skills and strategies that can be adapted to effectively interact with the spectrum of ages, developmental stages, neurodiversity and parental/carer involvement experienced in the acute paediatric setting.

Aggression management training programmes for staff working in acute care hospitals are scant $[7,8,13-21]$ and rarely described for staff working in the paediatric setting $[22,23]$. Programmes vary in format, content and duration hindering direct comparison. Outcome measures are variable in that most increase self-confidence in managing aggression $[7,8,13,14]$ and understanding of how to manage aggression; however, maintenance of skill acquisition is not routinely assessed. Programmes have not been shown to consistently reduce incidents of aggression or restraint $[13,16]$. Formats which include practice of skills combined with reflection and reinforcement, such as with simulation-based education, may be more efficacious [18, 24-26].

In order to improve staff skill levels in managing aggression, it would be ideal for staff to practise deescalation and restraint skills in an environment which closely resembles the environment in which they work $[18,26]$. Simulation training allows participants to develop or enhance their knowledge and skills, and analyse and respond to realistic situations in a simulated clinical setting without patient risk [27]. Simulation addresses the growing ethical issues around 'practice of skills' on human patients and provides a learning environment where staff can make mistakes, correct errors and rehearse the management of complex and crisis situations without compromising patient safety [25]. Another powerful effect of simulation training may be that it minimises participants from making mistakes in the future by providing them with opportunity to 'try out' strategies in a risk-free environment, improve their situation awareness and communication and leadership skills [25]. Simulation training to teach and practice resuscitation and other technical skills is well described in the paediatric acute care literature [28-30]. Similarly, the practice of non-technical skills such as communication techniques is also described in the simulation literature [31-33]. Simulation-based education may be an effective format to practice de-escalation skills for aggressive behaviour [34-38]. However, the use of simulation for teaching management of clinical aggression demonstrated by children and young people in the paediatric acute care setting has not been reported.

\section{Design and implementation}

This is a proof of concept study. The purpose was to design, implement and evaluate a simulation-based group training programme for health professionals which utilises real time training in an environment that closely replicates a clinical ward, with simulated adolescent patients who exhibit aggression whilst accessing hospital services.

The aims of this study were as follows:

- Evaluate the acceptability of this type of training for aggression management for staff for situations that involve typically developing children and young people

- Gain an understanding of the impact of the training on participants' perceived confidence in managing 
clinical aggression immediately, post-training and at 3-6 months follow-up.

\section{Evaluation framework}

The Kirkpatrick framework of training evaluation was utilised as it is the most widely used model to assess training [39-41]. It has been used in a number of studies to evaluate the simulation training [42-47] and training focussing on managing challenging behaviour [48, 49]. As this was a proof of concept study to test the acceptability of the training format, the evaluation outcomes were primarily designed to address Kirkpatrick levels 1 and 2 only (reaction and learning, respectively).

\section{Training design}

Clinical aggression is managed in the study hospital via a Code Grey response system. Code Grey is one of a series of emergency response codes used in hospitals in some states of Australia and is activated when aggressive or violent behaviour is identified [50]. This system involves a hospital emergency response to deal with people who are perceived to be or who are actively being aggressive towards another person. At the study hospital, an Australian tertiary paediatric hospital, a response team is activated to attend the incident which is led by a nurse with extensive clinical aggression management experience (Code Grey Coordinator), nurses from three wards and security staff who are all trained in aggression management. The response team works with the local staff to defuse the aggressive incident through verbal deescalation or restraint.

A 2-h simulation training programme was developed and embedded into the management of clinical aggression (MOCA) training programme at the study hospital from February 2017. This full day MOCA training [17, 51 ] is conducted by the Code Grey Coordinator and repeated monthly to build the capacity of the hospitalwide response team. Training is available for nursing, medical, allied health, education and security staff who may be involved in the Code Grey response. The course includes lectures on predictors and early warning signs of aggression, crisis assault cycle, communication strategies for managing aggression, legislation and local policies and physical intervention techniques. Annual attendance at MOCA training is mandatory for all staff working in the Mental Health Unit, for those enrolled in the Graduate Nurse Program, and newly employed security staff.

The RCH Simulation Program curriculum and simulation sessions are designed according to the concepts described by Dieckmann et al. [52], utilising the debriefing framework by Rudolph et al. [53]. This simulation-based education session included two separate simulations. The scenarios focused on managing aggression exhibited by a young person in the inpatient setting and were developed by the study investigators in conjunction with the simulation faculty. The simulation scenarios were reviewed, trialled and validated by members of the simulation faculty, with modifications made prior to conducting the sessions to improve the learning experience. Two simulation exercises were developed involving the same patient, a 15-year-old female named 'Danni', played by a professional actor (Table 1). Each simulation training session included a 10-min simulation followed by a 30-40 min facilitated debrief. The second scenario utilised the same scenario synopsis and task; however, the level of difficulty was escalated with the simulated patient instructed to react to staff interventions in a more aggressive manner.

Scenarios were designed to enable participants to primarily focus on applying supportive communication techniques and de-escalation skills to an aggressive situation. To ensure safety of the actor, the simulation was ceased by the simulation faculty if the participants decided the patient required 5-point prone restraint or chemical restraint despite de-escalation measures. Physical and chemical restraint, whilst discussed in the MOCA training day, are not deemed to be first line strategies in managing agitation and increasing aggression for young people in the acute hospital setting and therefore were not incorporated into this simulation training session.

The facilitated debrief explored participants' frames in order to analyse and reflect on their actions, discussed the communication framework for managing clinical aggression and enabled closure of any gaps in their knowledge.

Table 1 Simulation scenario synopsis

\section{Synopsis:}

Danni is a 15-year-old female with a history of mental health difficulties who was admitted to the Adolescent Unit for investigation of abdominal pain and management. Danni was sitting outside the entrance to the ward with another patient, Ned, playing games on their phones. Both patients were asked to return to the ward by a nurse who went looking for them. Ned returned immediately to the ward whilst Danni became distressed at being told what to do and stormed back to her bedroom. Danni locked herself in the bathroom after slamming the door.

Task:

Convince Danni to open the bathroom door and return to her bed. Use empathy and appropriate communication strategies to calm her and prevent further escalation in her behaviour.

Simulation learning objectives:

By the end of this simulation participants should be able to:

- Identify and demonstrate the key communication skills and language required when interacting with a distressed young person.

- Maintain safety of the patient.

- Demonstrate empathy and insight when communicating with the distressed young person.

- Recognise early warning signs of aggression and prevent behavioural escalations

- Recognise when it is appropriate to activate a Code Grey response. 


\section{Evaluation method}

The study design involved delivery of a 2-h simulationbased group training session on the management of clinical aggression to hospital staff with participants asked to complete three surveys: a pre-training survey, posttraining survey, and a follow-up survey. The purpose of the pre-training survey was to assess self-perceived levels of confidence and competence in managing clinical aggression. The purpose of the post-training survey was to assess if simulation training had an impact on participants' self-perception of confidence and competence in managing aggression. The purpose of the follow-up survey was to assess if the simulation training had a continued impact on participants' self-confidence and competence.

The principal investigator explained the study design to the participants prior to commencement of the simulation pre-brief. The simulation faculty member facilitating the simulation session then briefed participants on the objectives of the two simulation exercises. The roles and expectations of both the participants and the instructors were discussed. The structure of the session and the purpose of the post-simulation debrief was explained. The participants were informed that the same professional actor would play the role of the patient in each of the simulation exercises. The second simulation, whilst utilising the same scenario, was designed to be more complex than the first, providing participants with opportunity to extend their skills and build on knowledge learnt from the first simulation. Participants were asked to volunteer for roles in each simulation scenario. Eight volunteers were required for each scenario: two nurses to be the bedside nurses providing direct care to the patient, two additional nurses working in the ward and three nurses and one security staff member to join the Code Grey Coordinator as the Code Grey response team, if required. Allied health, medical and education staff could also volunteer to be part of the Code Grey team. Staff members were not asked to perform roles outside their scope of practice. After this pre-brief and establishment of participant roles, the simulation technologist orientated participants to the simulation centre and simulation equipment prior to commencement of the first simulation scenario. Participants, who did not have active roles in the first scenario, watched the simulation via live video stream in an adjacent room. Participants changed roles for the second scenario with observers offered the opportunity to be active participants. As group sizes varied from 10-25, not all participants were able to have an active role in one of the simulations; however, all had the opportunity to participate fully in the post-simulation debrief session. The skills required to de-escalate aggression in the simulation scenarios were discussed in the content of the MOCA training day with the simulation training providing an opportunity for participants to apply their knowledge and practice these de-escalation skills.

A short, written survey was administered to the participants' pre- (survey 1) and post-simulation training (survey 2) to assess acceptability of the training and selfperceived levels of confidence and competence immediately prior to and at completion of training.

A follow-up questionnaire (survey 3 ) was sent to participants as an electronic survey 3-6 months postsimulation training to assess their continued perceptions of the training and their exposure to aggression in the workplace. The surveys were completed anonymously with no identifying information. Results of the surveys were analysed for each training session and at completion of the study data was combined and analysed as a larger data set. Unique participant identifiers were not used; therefore, survey 1 and 2 results were not able to be linked to the results of survey 3 .

\section{Data security and handling}

De-identified hard copies and electronic files will be stored for 5 years in keeping with ethics requirements.

\section{Study setting and population}

The study setting is a tertiary paediatric hospital, The Royal Children's Hospital, (RCH) Melbourne, Australia.

The study was approved by The Royal Children's Hospital Melbourne Human Research Ethics Committee (HREC 37142). Health professionals including nursing, medical, allied health and education and security staff enrolled in the hospital MOCA training programme from February-December 2017 were invited to participate in the study. The participants were provided with study information in the form of a verbal script. Written consent to participate in the simulation-based training was gained and participants chose to participate in the study by completing the surveys. It was explained that participants could choose not to complete the surveys without explanation or consequence. In total, 146 staff completed the training in 2017, and it was anticipated that $90 \%$ would complete the immediate pre-/post-simulation survey.

Participants who completed the simulation training were invited via email to complete an electronic survey 36 months following completion of the simulation training. The survey link was emailed to participants. Two additional reminder emails were sent 2 weeks apart following the initial email. Participants could choose to participate in this part of the study by completing the survey. Participants could choose not to complete the survey without explanation or consequence. It was anticipated that $20 \%$ of participants would complete the survey.

All participants who attended the MOCA training were eligible to participate in the study. There were no 
exclusion criteria as all participants who work at the study hospital speak English and were able to complete the written survey.

The simulation-based education was conducted in the simulation centre using an environmental set-up which was a close replica of a hospital inpatient room, involved hospital staff performing roles similar to their current roles and utilised a trained actor as a simulated patient. As a result of this experience, it was recognised that participants could potentially become distressed during the simulation scenario training session. Supportive processes for debriefing and support were put into place in the event a participant became distressed during the training session.

\section{Statistical methods}

This study employed descriptive statistics, assessment of Likert scale questions and qualitative allocation to themes of written comments for the survey data. Quantitative data used a 5-point Likert scale to assess pretraining self-reported confidence and competence in managing clinical aggression as well as immediately following and 3-6 months following the training. The investigators used proportions of ratings, means, standard deviations and confidence intervals to describe the results. Means were used to analyse Likert data to provide more powerful understanding of the data [54-56]. Changes in self-perceived confidence were compared prior to and following the training using paired $t$ tests and reported at a group and individual level. We defined success as $80 \%$ of participants reporting an increase in confidence. The post- and follow-up groups were unsuitable for paired $t$ test comparisons of mean scores as the two samples were not independent and unable to be linked due to anonymity. The differences in mean confidence scores between the post- and follow-up group were presented in a descriptive manner.

\section{Evaluation findings \\ Participants}

Nine Management of Clinical Aggression (MOCA) training courses were conducted in 2017 for 146 participants. Ninety-five percent of participants completed the pre- and post-simulation questionnaires. Close to $40 \%$ of participants were graduate nurses who had recently commenced their Graduate Nurse Program, 44\% were ward nurses with the remainder of participants a mix of security staff, medical and allied health staff and nurses working in the mental health unit (Table 2).

Two thirds of participants (64\%) had minimal prior exposure to clinical aggression, with $44(31 \%)$ never witnessing a Code Grey, 26 (19\%) witnessing one, and 20 (14\%) witnessing two Code Greys. One group was more experienced in the management of clinical aggression
Table 2 Participant demographics

\begin{tabular}{|c|c|c|}
\hline & $\begin{array}{l}\text { Pre-training } \\
\boldsymbol{n}(\%) \\
\boldsymbol{N}=140\end{array}$ & $\begin{array}{l}\text { Follow-up } \\
\boldsymbol{n}(\%) \\
\boldsymbol{N}=44\end{array}$ \\
\hline Graduate nurse (GNP) & $55(39)$ & $16(36)$ \\
\hline RN & $51(36)$ & $12(27)$ \\
\hline $\begin{array}{l}\text { Clinical nurse specialist (CNS); clinical nurse } \\
\text { educator (CNE); associate nurse unit manager } \\
\text { (ANUM) }\end{array}$ & $11(8)$ & $5(11)$ \\
\hline Security staff & $9(6)$ & $1(2)$ \\
\hline Mental health RN & $7(5)$ & $6(14)$ \\
\hline Other & $4(3)$ & $2(5)$ \\
\hline Allied health professional & $2(1)$ & $2(5)$ \\
\hline Medical staff-trainee & $1(1)$ & $0(0)$ \\
\hline Staff $<1$ year experience & $69(49)$ & $16(36)$ \\
\hline Staff $>6$ years' experience & $34(24)$ & $11(25)$ \\
\hline Work in a mental health setting & $32(23)$ & $9(20)$ \\
\hline $\begin{array}{l}\text { Have been the recipient of clinical physical or } \\
\text { verbal aggression }\end{array}$ & $95(68)$ & $24(55)$ \\
\hline
\end{tabular}

CNS clinical nurse specialist, CNE clinical nurse educator, ANUM associate nurse unit manager, $R N$ registered nurse

with 29 (21\%) having participated in 10 or more Code Grey activations prior to the study.

\section{Acceptability}

At the completion of the simulation training, participants were asked to indicate how relevant they thought this training was to their work. Most of the participants, $123(88 \%)$, chose a rating of 4 or 5 out of 5 to indicate the level of relevance. All participants stated that they would recommend attendance at a simulated MOCA training session.

\section{Perceived confidence immediately after training}

Participants rated their confidence in managing clinical aggression $(1=$ not at all confident; $5=$ extremely confident) prior to the simulation training. Prior to undertaking training, $76 \%(n=106)$ rated their confidence as a 2 or 3 out of 5 with 1 indicating that they are not confident at all and 5 indicating they felt extremely confident. Immediately following completion of the training, $62 \%(n=87)$ rated their confidence as a 4 or 5 out of 5 .

Immediately after completing the simulation training, $81 \%(n=113)$ reported feeling more confident in managing clinical aggression. A 1-point increase in perceived confidence was reported by $46 \%(n=65)$ whilst $33 \%(n=46)$ of participants reported a 2- or 3-point increase. No change in perceived confidence was reported by $17 \%(n=24)$ whilst a small number of participants $(2 \%, n=3)$ reported feeling less confident in their skills after completing the training. 
Self-reported confidence in managing aggression increased significantly for all participants immediately following the training. Hospital staff who had not been exposed to clinical aggression prior to undertaking the training reported the greatest increase in perceived confidence post-training. In particular, graduate nurses reported the greatest increase in perceived confidence. Staff, other than graduate nurses, who had not been exposed to aggression and therefore not exposed to experiential learning, reported a greater increase in perceived confidence than those staff who had experienced aggression (Table 3). Paired $t$ tests were used to compare the difference in mean confidence levels pre- and posttraining. $P$ values for all groups were $<0.01$ indicating strong evidence to reject the null hypothesis, suggesting that training effects were maintained up to 6 months post-training.

At completion of the simulation training, participants felt most competent in the use of de-escalation techniques and maintaining patient safety. The largest gains in self-perceived competence as a result of completing the training were in hands on and off restraint and being a group leader (Table 4).

When asked about confidence to face clinical aggression in the future after the training, $80 \%$ of participants indicated that they thought they would be able to manage the situation as a result of completing the simulation training. Whilst no participants reported that they felt unable to manage aggression, $20 \%$ remained unsure of their ability to manage clinical aggression in the clinical environment.

\section{Perceived confidence 3-6 months after training}

Participants were asked to rate their perceived confidence levels in managing clinical aggression 3-6 months after the training. The response rate was $31 \%$ with 44 respondents completing the online survey. The respondents were representative of the larger group with a similar mix of graduate nurses, ward nurses and senior nurses (Table 2). The follow-up participants had similar levels of clinical aggression experience and the group included a similar mix of mental health versus non mental health staff.

At the 3-6 month follow-up, participants reported reasonable perceived confidence in managing aggression in their clinical environment. The mean perceived confidence score for follow-up participants (3.66, SD 0.71, CI $3.44,3.88)$ was similar to perceived confidence immediately following training (3.66, SD 0.71, CI 3.54, 3.78). Those participants who had experienced clinical aggression reported an increased mean perceived confidence score at follow-up (3.71, SD 0.55. CI 3.48, 3.94) compared to immediately post-training. Participants who had not experienced aggression reported similar but lower mean perceived confidence scores at follow-up (3.58, SD 0.90, CI 3.14, 4.01).

Self-reported confidence at follow-up was maintained when compared with perceived confidence levels immediately post-training.

\section{Reported experience 3-6 months after training}

Since attending the simulation training, $66 \%$ indicated that they had successfully managed clinical aggression, whilst the remaining $34 \%$ had not encountered clinical aggression since undertaking the training. At follow-up, staff who had experienced aggression since completion of the training reported improvements in perceived confidence in managing aggression. Graduate nurses who had not been exposed to aggression also reported further increases in perceived confidence compared to immediately post-training (Table 3 ).

\section{Discussion}

This is the first study to report development and evaluation of simulation training for paediatric acute care hospital staff in the management of adolescent aggression. Simulation training for this environment was considered an acceptable and worthwhile method of training and staff reported increased perceived confidence in managing clinical aggression following completion of the simulation training with perceived confidence levels maintained for up to 6 months. At follow-up, all

Table 3 Self-reported confidence levels of staff pre- and post-simulation training in managing clinical aggression

\begin{tabular}{|c|c|c|c|c|c|c|c|c|}
\hline \multirow{2}{*}{$\begin{array}{l}\text { How confident do you feel } \\
\text { managing clinical aggression? }\end{array}$} & \multirow[t]{2}{*}{$n$} & \multicolumn{2}{|l|}{ Pre-training } & \multicolumn{2}{|c|}{ Post-training } & \multicolumn{3}{|c|}{ Difference (post-pre) } \\
\hline & & $\overline{\text { Mean (SD) }}$ & $95 \% \mathrm{Cl}$ & $\overline{\text { Mean (SD) }}$ & $95 \% \mathrm{Cl}$ & Mean (SD) & $95 \% \mathrm{Cl}$ & $P$ value \\
\hline All participants & 138 & $2.49(0.88)$ & $(2.34,2.63)$ & $3.66(0.71)$ & $(3.54,3.78)$ & $1.17(0.90)$ & $(1.32,1.02)$ & $<0.01$ \\
\hline Experienced aggression & 95 & $2.62(0.88)$ & $(2.44,2.80)$ & $3.67(0.75)$ & $(3.52,3.83)$ & $1.05(0.96)$ & $(1.25,0.86)$ & $<0.01$ \\
\hline GNP & 24 & $2.25(0.85)$ & $(1.89,2.61)$ & $3.5(0.66)$ & $(3.22,3.78)$ & $1.25(1.11)$ & $(1.72,0.78)$ & $<0.01$ \\
\hline Other & 71 & $2.75(0.86)$ & $(2.54,2.95)$ & $3.73(0.77)$ & $(3.55,3.92)$ & $0.99(0.90)$ & $(1.20,0.77)$ & $<0.01$ \\
\hline Not experienced Aggression & 43 & $2.19(0.82)$ & $(1.93,2.44)$ & $3.63(0.62)$ & $(3.44,3.82)$ & $1.44(0.67)$ & $(1.65,1.24)$ & $<0.01$ \\
\hline GNP & 30 & $2(0.74)$ & $(1.72,2.28)$ & $3.53(0.63)$ & $(3.3,3.77)$ & $1.53(0.57)$ & $(1.75,1.32)$ & $<0.01$ \\
\hline Other & 13 & $2.62(0.87)$ & $(2.09,3.14)$ & $3.85(0.55)$ & $(3.51,4.18)$ & $1.23(0.83)$ & $(1.73,0.73)$ & $<0.01$ \\
\hline
\end{tabular}

GNP Graduate Nurse Program registered nurse 
Table 4 Self-reported competence in aggression management skills

\begin{tabular}{|c|c|c|c|c|c|c|c|c|c|}
\hline \multirow[t]{2}{*}{$\begin{array}{l}\text { How competent do you feel displaying these skills when faced with } \\
\text { clinical aggression? }\end{array}$} & \multicolumn{3}{|c|}{ Pre-training $(\boldsymbol{N}=140)$} & \multicolumn{3}{|c|}{ Post-training $(\boldsymbol{N}=140)$} & \multicolumn{3}{|c|}{$\begin{array}{l}\text { Follow-up, 3-6 months } \\
\text { post-training }(\boldsymbol{N}=44)\end{array}$} \\
\hline & $n$ & $\begin{array}{l}\text { Mean } \\
\text { (SD) }\end{array}$ & $95 \% \mathrm{Cl}$ & $n$ & $\begin{array}{l}\text { Mean } \\
(\mathrm{SD})\end{array}$ & $95 \% \mathrm{Cl}$ & $n$ & $\begin{array}{l}\text { Mean } \\
\text { (SD) }\end{array}$ & $95 \% \mathrm{Cl}$ \\
\hline Being a group leader & 138 & $\begin{array}{l}2.01 \\
(1.11)\end{array}$ & $\begin{array}{l}(1.82, \\
2.20)\end{array}$ & 137 & $\begin{array}{l}3.10 \\
(1.06)\end{array}$ & $\begin{array}{l}(2.92 \\
3.28)\end{array}$ & 44 & $\begin{array}{l}3.00 \\
(1.01)\end{array}$ & $(2.7,3.3)$ \\
\hline De-escalation communication techniques & 138 & $\begin{array}{l}2.80 \\
(0.84)\end{array}$ & $\begin{array}{l}(2.66, \\
2.94)\end{array}$ & 139 & $\begin{array}{l}3.73 \\
(0.76)\end{array}$ & $\begin{array}{l}(3.60, \\
3.86)\end{array}$ & 44 & $\begin{array}{l}3.73 \\
(0.79)\end{array}$ & $\begin{array}{l}(3.50 \\
3.96)\end{array}$ \\
\hline Maintaining patient safety & 139 & $\begin{array}{l}2.91 \\
(0.86)\end{array}$ & $\begin{array}{l}(2.77, \\
3.05)\end{array}$ & 139 & $\begin{array}{l}3.88 \\
(0.71)\end{array}$ & $\begin{array}{l}(3.76, \\
4.00)\end{array}$ & 44 & $\begin{array}{l}4.00 \\
(0.68)\end{array}$ & $(3.8,4.2)$ \\
\hline Hands off restraint & 139 & $\begin{array}{l}2.33 \\
(1.05)\end{array}$ & $\begin{array}{l}(2.16, \\
2.50)\end{array}$ & 135 & $\begin{array}{l}3.47 \\
(0.92)\end{array}$ & $\begin{array}{l}(3.31 \\
3.63)\end{array}$ & 44 & $\begin{array}{l}3.34 \\
(0.83)\end{array}$ & $\begin{array}{l}(3.09, \\
3.59)\end{array}$ \\
\hline Hands on restraint & 139 & $\begin{array}{l}2.15 \\
(1.22)\end{array}$ & $\begin{array}{l}(1.95, \\
2.35)\end{array}$ & 136 & $\begin{array}{l}3.25 \\
(0.96)\end{array}$ & $\begin{array}{l}(3.09, \\
3.41)\end{array}$ & 44 & $\begin{array}{l}3.07 \\
(0.10)\end{array}$ & $\begin{array}{l}(3.04, \\
3.10)\end{array}$ \\
\hline Administering chemical restraint & 136 & $\begin{array}{l}2.26 \\
(1.32)\end{array}$ & $\begin{array}{l}(2.04, \\
2.48)\end{array}$ & 130 & $\begin{array}{l}2.80 \\
(1.24)\end{array}$ & $\begin{array}{l}(2.59, \\
3.01)\end{array}$ & 44 & $\begin{array}{l}2.66 \\
(1.23)\end{array}$ & $\begin{array}{l}(2.30 \\
3.02)\end{array}$ \\
\hline
\end{tabular}

participants reported being able to manage clinical aggression. The simulation scenario, with use of a professional actor as the simulated patient, was identified by participants to be an acceptable form of training for the management of clinical aggression. This is consistent with findings of studies of nurses undertaking simulation training for the development of non-technical skills with some studies finding not only was the format acceptable, it was also the preferred method of learning [57-60].

The opportunity to rehearse and practice skills in an environment which closely resembles reality and develop critical thinking and clinical reasoning in a complex care situation without placing patients at risk is highly valued $[25,61]$ as is the importance of participating in simulated team training [62]. In addition, simulation provides opportunity for exposure to more challenging clinical interactions which clinicians are expected to manage competently despite having infrequent exposure [63].

This study confirmed that staff self-reported confidence levels in managing clinical aggression can be increased through completion of a 2 -h simulation training programme and adds to the body of literature that simulation training programmes can improve non-technical skills in health care staff: staff confidence [64], communication skills [33, 65], leadership skills [66-68], team skills $[28,69,70]$, knowledge acquisition and retention [71] and skills in aggression management [37, 38, 61, 72]. The use of a simulated patient exercise to practice de-escalation techniques has been described in some acute care hospitals $[12,18,20,21,61]$ and for undergraduate nursing students [37, 38]; however, widespread use of simulation courses for managing aggression in children and young people in acute health care, and in particular paediatric settings, has not been reported until this study. This proof of concept study provides evidence that simulation training is an acceptable and effective format to rehearse and practice de-escalation skills in the management of clinical aggression.

Newly registered clinicians (Graduate Nurse Program participants in this study) reported the greatest increase in perceived confidence levels in managing clinical aggression following completion of the training. The graduate nurses undertook the simulation training within the first month of their employment with most reporting minimal to no exposure to clinical aggressive incidents prior to the training. It was expected with minimal prior experience in managing aggression that their perceived confidence levels would be low prior to the training and increase following. This finding is consistent with other studies examining the theory-practice gap amongst newly qualified nurses. Simulation exercises in conjunction with other role modelling strategies have been found to reduce transitional stress, increase preparedness for practice and clinician confidence [73-75].

Decline in knowledge and skills following simulation training for health care providers has been well documented [76-78] with skills diminishing faster than knowledge [79]. We found that of the 33\% of respondents at 3-6 months follow-up, most reported they retained knowledge and perceived confidence. Two thirds of respondents reported they could manage aggression at follow-up. Confidence in patient management has been shown to be maintained in a number of simulation studies $[75,77,78,80]$ and even increased [81, 82] up to 1 year post-training. This study supports and extends the findings of de la Fuente and Schoenfisch [83] who reported nurses' confidence in coping with patient aggression to be higher in post behaviour management training and maintained up to 1 month following the training. Nursing staff from an adult medical unit who participated in an interactive programme utilising role plays for managing disruptive patient behaviours 
reported higher levels of knowledge, attitudes and confidence in managing disruptive at 3 months and 1 year post-training [19]. These studies indicate that selfreported knowledge and skills in aggression management can be maintained up for a year post-training. What is not clear in the literature is whether the use of simulation training is more effective at improving knowledge and skills than other commonly used training formats such as lectures or written or online learning packages. Organisational culture may influence the delivery, uptake and effectiveness of simulation-based group training programmes. Whilst there is evidence that simulation may be the most effective format for teaching and practicing clinical skills $[76,84,85]$, there is also evidence that institutional culture, with an emphasis on collaborative, interprofessional learning through simulation coupled with repeated exposure to clinical events, may increase confidence in managing clinical situations long term [82]. This concept is reinforced by this study where participants who had experienced clinical aggression post-training, reported increased perceived confidence at follow-up compared to immediately post-training. Another opportunity for skill maintenance is for simulation interventions to be followed by refresher courses. Refresher courses and adjustments to content delivery have been shown to have the greatest impact on skills retention in a systematic review of RCTs for structured resuscitation training [84].

Participants in our study reported being most competent in maintaining patient safety and de-escalation following training, and this was maintained at follow-up. Participants reported lower competence in being a group leader and implementing restraint which declined at follow-up. Our set of simulation scenarios were primarily focussed on the utilisation and practice of de-escalation skills and maintaining patient safety. Physical restraint is usually utilised when de-escalation methods are unsuccessful and/or patient or staff safety is threatened. The scenario was ceased prior to necessitating 5-point physical or chemical restraint to protect the simulated patient's safety. This simulation training programme was not designed to focus on using restraint as a first line measure but rather preventative aspects of aggression management, with implementation of a repertoire of de-escalation techniques individually selected and adapted according to the changing clinical situation. If health care organisations consider leadership and competent use of physical and chemical restraint to be key skills for acute care staff, the simulation scenarios can be adjusted, or new scenarios developed, and trialled with these key learning objectives in mind.

\section{Challenges experienced}

Delivering this innovation to nine different training groups enabled us to identify challenges and develop and implement mitigation strategies to improve consistency in experience. One challenge noted was that of participant anxiety. Participants frequently verbalised performance anxiety prior to the simulation sessions even if they had prior simulation experience. To ameliorate anxiety, simulation staff, in a briefing prior to all simulation sessions, provided reinforcement that the experience is a confidential space for learning and reflection. Heightened anxiety was likely due to the large number of junior staff participating or a lack of experience with simulation-based education. In future, we plan to assess the quality and impact on anxiety of our prebriefing session.

Due to the large number of staff attending each training session, not all participants were able to participate in the simulation scenario and not all participating had key roles during the simulated scenario. Only one participant per scenario could assume the role of group leader so most participants did not practise group leadership skills. However, all participants were able to contribute during the debrief, whether or not they participated in, or observed the scenario, to enable reflection and learning. The debrief at the end of each session addressed scenario objectives and dissected the issues that evolved for this group and the actor. Leadership skills were addressed, and actor feedback and coaching informed the subsequent training sessions to contribute to group learning. Another additional future improvement will be to provide a learning tool that is relevant to the content, for observers to complete whilst watching the simulated scenario [86].

\section{Limitations}

This study was a proof of concept study conducted in one acute care paediatric hospital and as such, the authors did not intend to demonstrate the intervention would have a significant impact on practice. Rather, the aim was to assess if this training innovation is acceptable to participants with the view to design more complex simulations involving young people with autism spectrum disorder and aggressive behaviours and evaluate the effectiveness of this training for acute care paediatric hospital staff in a future trial. Randomised controlled trials which involve multiple sites will provide greater evidence about the effectiveness of this training format. Simulation programmes delivered by trained simulation educators can be replicated in numerous settings to provide larger data sets and stronger evidence in terms of clinical outcomes [28, 87-89].

Only $33 \%$ of study participants completed the followup survey. It was a purposeful decision to use paperbased pre- and post-surveys for the training groups to ensure optimal response rate. It was not practical to deliver a paper-based follow-up survey to participants located in various departments and wards of the 
organisation, so an electronic survey was sent. It was anticipated that response rates would be lower with this method as staff may not read emails and may have left the organisation. We cannot be confident that the results of follow-up are true for the whole group. Whilst we were able to perform paired $t$ tests on the pre- and posttraining group mean perceived confidence scores, this analysis was unsuitable for the post- and follow-up group, as the two samples were not independent and unable to be linked due to anonymity. The differences in mean perceived confidence scores between the post- and follow-up group were, therefore, presented in a descriptive manner.

The design of the simulation scenarios focussed on supportive communication strategies and de-escalation skills rather than the use of major physical and chemical restraint. The use of two-point, upper body restraint techniques was allowed in these simulation scenarios as they posed minimal risk of injury to the actor. Participants rated their perceived confidence in managing full body and chemical restraint lower than other aggression management strategies as expected given the limitation of not including this content in the simulation exercise.

Whilst the majority of participants were nursing staff, with a minority including security, allied health and medical staff, this is a true reflection of the make-up of the Code Grey response team who manages the episodes of clinical aggression in this paediatric hospital. Future studies could compare training programmes which include a more even distribution of professions when appropriate for their hospital setting.

All participants completed the didactic training sessions on aggression management for $6 \mathrm{~h}$ prior to commencing the simulation-based group training. We did not assess perceived confidence prior to commencing the training day, which is a limitation of this study. Self-reported confidence levels were, however, reported immediately prior to and following the simulation. In considering the impact of this simulation training, this study utilises the Kirkpatrick Model to evaluate the effect on reaction and learning (levels 1 and 2). Future studies with more comprehensive outcome measures will be able to address the effects on staff behaviour and patient outcomes (levels 3 and 4) [88, 90]. It was the intent of this study to ensure the training format was acceptable for participants and effective in addressing perceived confidence prior to expanding the programme, increasing the scenario complexity and measuring the impact on clinical outcomes. In the future, larger trials are needed that address all four Kirkpatrick levels in order to influence organisational change and demonstrate return on investment of the training.

\section{Implications for practice and future research}

The findings from this study support further development of training programmes to provide education about managing clinical aggression in the paediatric setting, and assessment of effectiveness should be completed. The findings from this proof of concept study may have important implications for a variety of paediatric acute health care settings that are currently experiencing clinical aggression on a daily basis. This study may prompt acute care hospitals to revise their aggression management training to ensure response mechanisms promote physical and psychological safety for staff, and ultimately optimise care for children with neurodiversity and aggressive behaviours.

\section{Conclusions}

Paediatric acute hospital settings are reporting increasing frequency of aggression. Action is needed to support staff to prevent, ameliorate and best manage aggression. This proof of concept study is the first to evaluate a simulation training programme for acute paediatric health professionals on managing clinical aggression in young people. The findings of this study suggest that simulation training for clinical aggression management may be an important addition to staff training programmes in acute care hospitals. Acute care hospitals have a duty to ensure staff are adequately trained and have confidence in hospital systems and processes should aggression be experienced. Further research in this area is warranted, to assess if simulation training will prevent aggressive episodes, reduce patient distress and optimise care through enhancing not only staff confidence, but also competence in managing these patients.

\section{Abbreviations \\ MOCA: Management of Clinical Aggression; GNP: Graduate Nurse Program; CNS: Clinical nurse specialist; CNE: Clinical nurse educator; ANUM: Associate nurse unit manager; RN: Registered nurse; $\mathrm{MH}$ : Mental health}

\section{Acknowledgements}

The authors would like to acknowledge the Royal Children's Hospital Simulation Faculty, the Code Grey Coordinators and Ms Poh Chua for their assistance with this study.

\section{Authors' contributions}

All authors contributed to the design and implementation of the project. All authors contributed to the writing of the manuscript, including editing and approval of the final product.

\section{Funding}

This study fulfils part of the requirements for MM's PhD candidature and is funded in part by an Australian Government Research Training Program Australian Government Research Training Program, Elizabeth \& Vernon Puzey Scholarship and the Rowden White Scholarship. At the time of the study, MM was in a Royal Children's Hospital Simulation Fellowship position supported by The Royal Children's Hospital Foundation Simulation Grant (ID 2013-124).

The funders have no input into the planning or conduct of this review or the interpretation or publication of the study's findings.

Availability of data and materials

The datasets used and analysed during the study are available from the corresponding author on reasonable request. 


\section{Ethics approval and consent to participate}

The study was approved by The Royal Children's Hospital Melbourne Human Research Ethics Committee (HREC 37142). Health professionals enrolled in the hospital MOCA training programme from February-December 2017 were invited to participate in the study. Consent to participate in the study was not required by the HREC as responses were anonymous.

\section{Consent for publication}

Not applicable

\section{Competing interests}

The authors declare they have not competing interests.

\section{Author details}

${ }^{1}$ Neurodevelopment \& Disability, Royal Children's Hospital, 50 Flemington Road, Parkville, Victoria 3052, Australia. ${ }^{2}$ Department of Paediatrics, The University of Melbourne, 50 Flemington Road, Parkville, Victoria 3052, Australia. ${ }^{3}$ Murdoch Children's Research Institute, 50 Flemington Road, Parkville, Victoria 3052, Australia. ${ }^{4}$ Department of Nursing, The University of Melbourne, 50 Flemington Road, Parkville, Victoria 3052, Australia. ${ }^{5}$ Nursing Research, Nursing Education, Royal Children's Hospital, 50 Flemington Road, Parkville, Victoria 3052, Australia. ${ }^{6}$ The RCH Simulation Program, Royal Children's Hospital, 50 Flemington Road, Parkville, Victoria 3052, Australia. ${ }^{7}$ Department of Paediatrics, Education and Research, Monash Children's Hospital, Monash University, 246 Clayton Road, Clayton, Victoria 3168, Australia.

Received: 12 January 2020 Accepted: 22 July 2020

Published online: 12 August 2020

\section{References}

1. Johnson N, Lashley J, Stonek A, Bonjour A. Children with developmental disabilities at a pediatric hospital: staff education to prevent and manage challenging behaviors. J Pediatr Nurs. 2012;27(6):742-9.

2. Hopper S, Babl F, Stewart C, Woo J. Aggression management in a children's hospital setting. Med J Aust. 2012;196(3):198-201.

3. Malas N, Spital L, Fischer J, Kawai Y, Cruz D, Keefer P. National survey on pediatric acute agitation and behavioral escalation in academic inpatient pediatric care settings. Psychosomatics. 2017;58(3):299-306.

4. Mitchell M, Newall F, Williams K. Autism spectrum disorder and challenging behaviours demonstrated in a paediatric hospital environment. Poster session presented at: International Society of Autism Research (INSAR) Annual Meeting. Rotterdam: The Netherlands; 2018.

5. Mitchell MJ, Newall FH, Sokol J, Williams KJ. Simulation-based education for staff managing aggression and externalizing behaviors in children with autism spectrum disorder in the hospital setting: pilot and feasibility study protocol for a cluster randomized controlled trial. JMIR Res Protoc. 2020;9(6): e18105

6. Truman A, Goldman M, Lehna C, Berger J, Topp R. Verbal abuse of pediatric nurses by patients and families. Kentucky Nurse. 2013;61(1):6-8.

7. Deans $C$. The effectiveness of a training program for emergency department nurses in managing violent situations. Aust J Adv Nursing. 2004;21(4):17-22.

8. Ferrara K, Davis-Ajami M, Warren J, Murphy L. De-escalation training to medical-surgical nurses in the acute care setting. Issues Ment Health Nurs. 2017;38(9):742-9.

9. Grenyer B, Ilkiw-Lavalle O, Biro P, Middleby-Clements J, Comninos A, Coleman M. Safer at work: development and evaluation of an aggression and violence minimization program. Aust N Z J Psychiatry. 2004;38(10):804-10.

10. Hills D. Relationships between aggression management training, perceived self-efficacy and rural general hospital nurses' experiences of patient aggression. Contemp Nurse. 2008;31(1):20-31.

11. IIkiw-Lavalle O, Grenyer B, Graham L. Does prior training and staff occupation influence knowledge acquisition from an aggression management training program? Int J Ment Health Nurs. 2002;11(4):233-9.

12. Schwartz F, Bjorklund P. Quality improvement project to manage workplace violence in hospitals: lessons learned. J Nurs Care Qual. 2018;00(00):1-7.

13. Heckemann B, Zeller A, Hahn S, Dassen T, Schols J, Halfens R. The effect of aggression management training programmes for nursing staff and students working in an acute hospital setting. A narrative review of current literature. Nurse Educ Today. 2015;35(1):212-9.

14. Baig L, Tanzil S, Shaikh S, Hashmi I, Khan M, Polkowski M. Effectiveness of training on de-escalation of violence and management of aggressive behavior faced by health care providers in a public sector hospital of Karachi. Pakistan J Med Sci. 2018;34(2):294-9.

15. Gerdtz M, Daniel C, Dearie V, Prematunga R, Bamert M, Duxbury J. The outcome of a rapid training program on nurses' attitudes regarding the prevention of aggression in emergency departments: a multi-site evaluation. Int J Nurs Stud. 2013;50(11):1434-45.

16. Kynoch K, Wu C, Chang A. Interventions for preventing and managing aggressive patients admitted to an acute hospital setting: a systematic review. Worldviews Evid-Based Nurs. 2011;8(2):76-86.

17. Forster J, Petty M, Schleiger C, Walters H. kNOw workplace violence: developing programs for managing the risk of aggression in the health care setting. Med J Aust. 2005;183(7):357-61.

18. Krull W, Gusenius TM, Germain D, Schnepper L. Staff perception of interprofessional simulation for verbal de-escalation and restraint application to mitigate violent patient behaviors in the emergency department. J Emerg Nurs. 2019;45(1):24-30.

19. Lee B, Del Rosario K, Byron-lyamah C. Incorporating relationship-based care into a nurse education program for managing disruptive patient behaviors. Clin Nurse Spec. 2017;31(4):201-9.

20. Wong $A H$, Auerbach MA, Ruppel $H$, Crispino $L$, Rosenberg A, lennaco JD, et al. Addressing dual patient and staff safety through a team-based standardized patient simulation for agitation management in the emergency department. Simul. 2018;13(3):154-62.

21. Wu J-C, Chen H-Y, Lee Hsieh J, Clinciu DL, Tung H-H. Enhancing health care personnel's response to ER violence using situational simulation. Clinical Simulation in Nursing. 2019;28:6-14.

22. Abraham A, Cheng TL, Wright JL, Addlestone I, Huang Z, Greenberg L. Assessing an educational intervention to improve physician violence screening skills. Pediatrics. 2001;107(5):E68.

23. Enriquez D, Gomez Traverso R, Szyld E. Colaboradores. Behavior of pediatric medical residents during a clinical simulation of a violent mother in a pediatric emergency. Arch Argent Pediatr. 2016;114(3):232-6.

24. Eddy K, Jordan Z, Stephenson M. Health professionals' experience of teamwork education in acute hospital settings: a systematic review of qualitative literature. JBI Database System Rev Implement Rep. 2016;14(4):96-137.

25. Lewis $R$, Strachan A, Smith M. Is high fidelity simulation the most effective method for the development of non-technical skills in nursing? A review of the current evidence. Open Nurs J. 2012;6:82-9.

26. Vestal HS, Sowden G, Nejad S, Stoklosa J, Valcourt SC, Keary C, et al. Simulationbased training for residents in the management of acute agitation: a cluster randomized controlled trial. Acad Psychiatry. 2017:41(1):62-7.

27. Pilcher J, Goodall H, Jensen C, Huwe V, Jewell C, Reynolds R, et al. Special focus on simulation: educational strategies in the NICU: simulation-based learning: It's not just for NRP. Neonatal Network. 2012;31(5):281-7.

28. Gilfoyle E, Koot D, Annear J, Bhanji F, Cheng A, Duff J, et al. Improved clinical performance and teamwork of pediatric interprofessional resuscitation teams with a simulation-based educational intervention. Pediatr Crit Care Med. 2017;18(2):e62-e9.

29. Rovamo L, Nurmi E, Mattila M, Suominen P, Silvennoinen M. Effect of a simulation-based workshop on multidisplinary teamwork of newborn emergencies: an intervention study. BMC Res Notes. 2015;8:671.

30. Steinemann S, Berg B, Skinner A, DiTulio A, Anzelon K, Terada K, et al. In situ, multidisciplinary, simulation-based teamwork training improves early trauma care. J Surg Educ. 2011;68(6):472-7.

31. Bateman L, Tofil N, White M, Dure L, Clair J, Needham B. Physician communication in pediatric end-of-life care: a simulation study. Am J Hospice Palliative care. 2016;33(10):935-41.

32. Henner N, Boss R. Neonatologist training in communication and palliative care. Semin Perinatol. 2017:41(2):106-10.

33. Johnson E, Hamilton M, Watson R, Claxton R, Barnett M, Thompson A, et al. An intensive, simulation-based communication course for pediatric critical care medicine fellows. Pediatr Crit Care Med. 2017;18(8):e348-e55.

34. Nau J. A training course in aggression management for nursing students: its aims, contents and benefits. In Needham, I. et al editors. Towards safety, security and wellbeing for all. Proceedings of the Fourth International Conference on Violence in the Health Sector; 2014 Oct 22-24; Miami, USA. Amsterdam: Kavanah; 2014 p. 111-5. 
35. Feinstein R. Violence prevention education program for psychiatric outpatient departments. Acad Psychiatry. 2014;38(5):639-46.

36. Krull W, Gusenius T, Germain D, Schnepper L. Staff Perception of Interprofessional Simulation for Verbal De-escalation and Restraint Application to Mitigate Violent Patient Behaviors in the Emergency Department. J Emerg Nurs. 2019;45(1):24-30.

37. Martinez A. Implementing a workplace violence simulation for undergraduate nursing students: a pilot study. J Psychosoc Nurs Ment Health Serv. 2017;55(10):39-44.

38. Nau J, Halfens R, Needham I, Dassen T. Student nurses' de-escalation of patient aggression: a pretest-posttest intervention study. Int J Nurs Stud. 2010;47(6):699-708.

39. Kirkpatrick D. Evaluating Training Programs: The Four Levels. 3rd ed. San Francisco: Berrett-Koehler Publishers; 2006.

40. Kirkpatrick D, Kirkpatrick J. Implementing the four levels: a practical guide for effective evaluation of training programs. San Francisco: Berrett-Koehler Publishers; 2007

41. Watkins R, Leigh D, Foshay R, Kaufman R. Kirkpatrick plus: evaluation and continuous improvement with a community focus. Educ Technol Res Dev. 1998;46(4):90-6.

42. Sharma $P$, Sharma $P$, Herbert J, Singh M. Nurses' training evaluation: an assessment of effective transfer of simulation training. Int J Nurs Res. 2018; $4(2): 78-84$.

43. Boet S, Bould M, Fung L, Qosa H, Perrier L, Tavares W, et al. Transfer of learning and patient outcome in simulated crisis resource management: a systematic review. Canadian journal of anaesthesia $=$ Journal canadien d'anesthesie. 2014:61(6):571-82.

44. Adamson K, Kardong-Edgren S, Willhaus J. An updated review of published simulation evaluation instruments. Clin Simul Nursing. 2013;9(9):e393-400.

45. Fransen AF, Banga FR, van de Ven J, Mol BWJ, Oei SG. Multi-professional simulation-based team training in obstetric emergencies for improving patient outcomes and trainees' performance. Cochrane Database Syst Rev. 2015, Issue 2. Art. https://doi.org/10.1002/14651858.CD011545

46. Gordon M, Darbyshire D, Baker P. Non-technical skills training to enhance patient safety: a systematic review. Med Educ. 2012;46(11):1042-54.

47. Kaplonyi J, Bowles K, Nestel D, Kiegaldie D, Maloney S, Haines T, et al. Understanding the impact of simulated patients on health care learners' communication skills: a systematic review. Med Educ. 2017; 51(12):1209-19.

48. Smidt A, Balandin S, Sigafoos J, Reed V. The Kirkpatrick model: a useful tool for evaluating training outcomes. J Intellect Develop Disabil. 2009; 34(3):266-74.

49. Oostrom J, van Mierlo H. An evaluation of an aggression management training program to cope with workplace violence in the healthcare sector. Res Nurs Health. 2008;31(4):320-8.

50. Royal Children's Hospital Melbourne. Clinical Practice Guidelines: Acute Behavioural Disturbance: Code Grey [Internet]. Melbourne: The Royal Children's Hospital; 2017 [updated July 2017. Available from: https://www. rch.org.au/clinicalguide/guideline_index/acute_behavioural_disturbance_ code_grey/.

51. Northern Health. Annual Report: 2017-2018 Annual report [Internet]. Melbourne: Northern Health; 2018. Available from https://www.nh.org.au/ publications/annual-report/.

52. Dieckmann P, Gaba D, Rall M. Deepening the theoretical foundations of patient simulation as social practice. Simul Healthc. 2007;2(3):183-93.

53. Rudolph JW, Simon R, Rivard P, Dufresne RL, Raemer DB. Debriefing with good judgment: combining rigorous feedback with genuine inquiry. Anesthesiol Clin. 2007;25(2):361-76

54. Carifio J, Perla R. Ten Common Misunderstandings, Misconceptions, Persistent Myths and Urban Legends about Likert Scales and Likert Response Formats and their Antidotes. J Soc Sci. 2007;3(3):106-116.

55. Carifio J, Perla R. Resolving the 50-year debate around using and misusing Likert scales. Med Educ. 2008;42(12):1150-2.

56. Norman G. Likert scales, levels of measurement and the "laws" of statistics. Adv Health Sci Educ. 2010;15(5):625-32.

57. Ballangrud R, Hall-Lord M, Hedelin B, Persenius M. Intensive care unit nurses' evaluation of simulation used for team training. Nurs Critical Care. 2014; 19(4):175-84.

58. Jeffries P, Rizzolo M. NLN/Laerdal project summary report. Designing and implementing models for the innovative use of simulation to teach nursing care of ill adults and children: A national multi-site study. New York:
National League for Nursing; 2006. Available from http://www.nln.org/docs/ defaultsource/professional-development-programs/read-the-nln-laerdalproject-summary-report-pdf.pdf?sfvrsn=0.

59. Levett-Jones T, Andersen P, Reid-Searl K, Guinea S, McAllister M, Lapkin S, et al. Tag team simulation: an innovative approach for promoting active engagement of participants and observers during group simulations. Nurse Educ Pract. 2015;15(5):345-52.

60. Zapko K, Ferranto M, Blasiman R, Shelestak D. Evaluating best educational practices, student satisfaction, and self-confidence in simulation: a descriptive study. Nurse Educ Today. 2018;60:28-34.

61. Wong A, Wing L, Weiss B, Gang M. Coordinating a team response to behavioral emergencies in the emergency department: a simulation-enhanced interprofessional curriculum. West J Emerg Med. 2015;16(6):859-65.

62. Strachan A, Graham A, Hormis A, Hilton G. What were the perceptions of primary care teams on learning from a single multidisciplinary simulationbased training intervention? Educ Prim Care. 2011;22(4):229-34.

63. MacLean S, Kelly M, Geddes F, Della P. Use of simulated patients to develop communication skills in nursing education: an integrative review. Nurse Educ Today. 2017:48:90-8.

64. Ajaz A, David R, Bhat M. The PsychSimCentre: teaching out-of-hours psychiatry to non-psychiatrists. Clin Teach. 2016;13(1):13-7.

65. Anderson H, Young J, Marrelli D, Black R, Lambreghts K, Twa M. Training students with patient actors improves communication: a pilot study. Optom Vis Sci. 2014;91(1):121-8.

66. Endacott R, Bogossian F, Cooper S, Forbes H, Kain V, Young S, et al. Leadership and teamwork in medical emergencies: performance of nursing students and registered nurses in simulated patient scenarios. J Clin Nurs. 2015:24(1-2):90-100.

67. Smith S, Farra S, Dempsey A, Arms D. Preparing nursing students for leadership using a disaster-related simulation. Nurse Educ. 2015:40(4):212-6.

68. Fernandez Castelao E, Boos M, Ringer C, Eich C, Russo S. Effect of CRM team leader training on team performance and leadership behavior in simulated cardiac arrest scenarios: a prospective, randomized, controlled study. BMC Med Educ. 2015;15:116.

69. Merchant D. Does high-fidelity simulation improve clinical outcomes? Jurses Staff Dev. 2012;28(1):E1-8 quiz E9-10.

70. Murphy $M$, Curtis $K$, McCloughen $A$. What is the impact of multidisciplinary team simulation training on team performance and efficiency of patient care? An integrative review. Australas Emerg Nurs J. 2016;19(1):44-53.

71. Akhu-Zaheya L, Gharaibeh M, Alostaz Z. Effectiveness of simulation on knowledge acquisition, knowledge retention, and self-efficacy of nursing students in Jordan. Clin Simul Nursing. 2013;9(9):e335-e42.

72. Wong A, Auerbach M, Ruppel H, Crispino L, Rosenberg A, lennaco J, et al. Addressing dual patient and staff safety through a team-based standardized patient simulation for agitation management in the emergency department. Simul Healthc. 2018;13(3):154-62

73. Monaghan T. A critical analysis of the literature and theoretical perspectives on theory-practice gap amongst newly qualified nurses within the United Kingdom. Nurse Educ Today. 2015;35(8):e1-7.

74. Edwards D, Hawker C, Carrier J, Rees C. A systematic review of the effectiveness of strategies and interventions to improve the transition from student to newly qualified nurse. Int J Nurs Stud. 2015;52(7):1254-68.

75. Edwards D, Hawker C, Carrier J, Rees C. The effectiveness of strategies and interventions that aim to assist the transition from student to newly qualified nurse. JBI Lib Syst Rev. 2011;9(53):2215-323.

76. Madani A, Watanabe $Y$, Vassiliou M, Fuchshuber P, Jones D, Schwaitzberg S, et al. Long-term knowledge retention following simulation-based training for electrosurgical safety: 1-year follow-up of a randomized controlled trial. Surg Endosc. 2016;30(3):1156-63.

77. Nelissen E, Ersdal H, Mduma E, Evjen-Olsen B, Broerse J, van Roosmalen J, et al. Helping mothers survive bleeding after birth: retention of knowledge, skills, and confidence nine months after obstetric simulation-based training. BMC Pregnancy Childbirth. 2015;15:190.

78. Vadnais M, Dodge L, Awtrey C, Ricciotti H, Golen T, Hacker M. Assessment of long-term knowledge retention following single-day simulation training for uncommon but critical obstetrical events. J Matern Fetal Neonatal Med. 2012;25(9):1640-5.

79. Yang C, Yen Z, McGowan J, Chen H, Chiang W, Mancini M, et al. A systematic review of retention of adult advanced life support knowledge and skills in healthcare providers. Resuscitation. 2012;83(9):1055-60. 
80. Crowe S, Ewart L, Derman S. The impact of simulation based education on nursing confidence, knowledge and patient outcomes on general medicine units. Nurse Educ Pract. 2018;29:70-5.

81. Langhan T, Rigby I, Walker I, Howes D, Donnon T, Lord J. Simulation-based training in critical resuscitation procedures improves residents' competence. CJEM. 2009;11(6):535-9.

82. McLaughlin C, Wieck M, Barin E, Rake A, Burke R, Roesly H, et al. Impact of simulation-based training on perceived provider confidence in acute multidisciplinary pediatric trauma resuscitation. Pediatr Surg Int. 2018;34(12): 1353-62.

83. de la Fuente M, Schoenfisch A. Impact of behavior management training on nurses' confidence in managing patient aggression. J Nurs Adm. 2019; 49(2):73-8.

84. Au K, Lam D, Garg N, Chau A, Dzwonek A, Walker B, et al. Improving skills retention after advanced structured resuscitation training: a systematic review of randomized controlled trials. Resuscitation. 2019;138:284-96.

85. McGaghie W, Issenberg S, Cohen E, Barsuk J, Wayne D. Does simulationbased medical education with deliberate practice yield better results than traditional clinical education? A meta-analytic comparative review of the evidence. Acad Med. 2011;86(6):706-11.

86. O'Regan S, Molloy E, Watterson L, Nestel D. Observer roles that optimise learning in healthcare simulation education: a systematic review. Adv Simul. 2016;1(1):4.

87. Chung C, Cooper S, Cant R, Connell C, McKay A, Kinsman L, et al. The educational impact of web-based and face-to-face patient deterioration simulation programs: an interventional trial. Nurse Educ Today. 2018;64:93-8.

88. Cheng A, Kessler D, Mackinnon R, Chang T, Nadkarni V, Hunt E, et al. Conducting multicenter research in healthcare simulation: Lessons learned from the INSPIRE network. Adv Simul. 2017;2:6.

89. Siassakos D, Bristowe K, Hambly H, Angouri J, Crofts J, Winter C, et al. Team communication with patient actors: findings from a multisite simulation study. Simul Healthc. 2011;6(3):143-9.

90. Gaba D. The future vision of simulation in health care. Qual Safety Health Care. 2004;13(suppl 1):i2-i10.

\section{Publisher's Note}

Springer Nature remains neutral with regard to jurisdictional claims in published maps and institutional affiliations.

Ready to submit your research? Choose BMC and benefit from:

- fast, convenient online submission

- thorough peer review by experienced researchers in your field

- rapid publication on acceptance

- support for research data, including large and complex data types

- gold Open Access which fosters wider collaboration and increased citations

- maximum visibility for your research: over $100 \mathrm{M}$ website views per year

At $\mathrm{BMC}$, research is always in progress.

Learn more biomedcentral.com/submissions 